\section{Correction: Induction of circulating T follicular helper cells and regulatory T cells correlating with HIV-1 gp120 variable loop antibodies by a subtype $C$ prophylactic vaccine tested in a Phase I trial in India}

\section{The PLOS ONE Staff}

\section{Notice of Republication}

This article was republished on September 7, 2018 to correct an error to the ORCID iD of the corresponding author introduced during the typesetting process. The publisher apologizes for the error. Please download this article again to view the correct version.

In addition, the corresponding author's name has been corrected. The correct name is: Hanna Elizabeth Luke.

\section{Reference}

1. Munusamy Ponnan S, Swaminathan S, Tiruvengadam K, K. K. V, Cheedarla N, Nesakumar M, et al. (2018) Induction of circulating T follicular helper cells and regulatory T cells correlating with HIV-1 gp120 variable loop antibodies by a subtype $C$ prophylactic vaccine tested in a Phase I trial in India. PLoS ONE 13(8): e0203037. https://doi.org/10.1371/journal.pone.0203037 PMID: 30157242

\section{f open ACCEsS}

Citation: The PLOS ONE Staff (2018) Correction: Induction of circulating $T$ follicular helper cells and regulatory T cells correlating with HIV-1 gp120 variable loop antibodies by a subtype $C$ prophylactic vaccine tested in a Phase I trial in India. PLOS ONE 13(9): e0204476. https://doi.org/ 10.1371/journal.pone.0204476

Published: September 19, 2018

Copyright: @ 2018 The PLOS ONE Staff. This is an open access article distributed under the terms of the Creative Commons Attribution License, which permits unrestricted use, distribution, and reproduction in any medium, provided the original author and source are credited. 